\title{
CAPTAÇÃO DE RECURSOS TECNOLÓGICOS PARA ORGANIZAÇÕES DO TERCEIRO
}

\author{
SETOR
}

\author{
Carina Nunes ${ }^{1}$ \\ http://orcid.org/0000-0003-0734-3463 \\ Melissa Watanabe 2 \\ http://orcid.org/0000-0003-2205-6235 \\ Erico Souza Costa ${ }^{3}$ \\ https://orcid.org/0000-0002-8556-888X
}

Recebido em: 18 out. 2019

Aceito em: $07 \mathrm{fev} .2020$

Como citar este artigo: NUNES, Carina; WATANABE, Melissa; COSTA, Erico Souza. CAPTAÇÃO DE RECURSOS TECNOLÓGICOS PARA ORGANIZAÇÕES DO TERCEIRO SETOR. Revista Visão:

Gestão Organizacional, Caçador, SC, Brasil, v.9, n.2, p. 20-31, jul./dez. 2020. Disponível em: http://dx.doi.org/10.33362/visao.v9i2.2142.

Resumo: Na década de 1990 um processo de reestruturação nas organizações não governamentais veio a culminar tanto no desenvolvimento do empreendedorismo social, quanto na profissionalização do terceiro setor. Uma das principais dificuldades dessas organizações ainda está centrada na captação de recursos para manter as suas atividades em funcionamento. Pesquisadores nesta área do conhecimento indicam que os recursos arrecadados devem ser advindos de diferentes segmentos da sociedade como de empresas, pessoas, vendas de material próprio, entre outros. O campo tecnológico, embora em expansão, ainda é pouco explorado como um meio de captação de recursos para organizações sem fins lucrativos. Assim, esta pesquisa tem por objetivo elencar possibilidades de captação de recursos tecnológicos disponíveis às entidades do terceiro setor, e evidenciar de que maneira tais recursos podem ser acessados. Quanto aos processos metodológicos, esta é uma pesquisa exploratória, documental e descritiva, realizada por meio de dados secundários coletados no website de uma empresa do ramo de tecnologias para o setor sem fins lucrativos. Dentre os principais resultados, identificou-se a possibilidade de acesso gratuito a ferramentas tais como Ad Grants, YouTube, GSuit, bem como o acesso às licenças de Softwares da Microsoft ${ }^{\circledR}$. Assim, as possibilidades de captação de recursos utilizando ferramentas disponíveis em ciberespaços podem potencializar as atividades fins de organizações sociais.

Palavras-Chave: Tecnologia, organização sem fins lucrativos, Google, TechSoup.

\footnotetext{
${ }^{1}$ Bacharel em Administração de Empresas pela Universidade do Extremo Sul Catarinense (UNESC), Mestre pelo Programa de Pós-Graduação em Desenvolvimento Socioeconômico (PPGDS/UNESC) e Doutoranda em Desenvolvimento Socioeconômico (PPGDS/UNESC). E-mail: carinanunesadm@gmail.com.

2 Professora permanente do Programa de Pós-Graduação em Desenvolvimento Socioeconômico (PPGDS) da Universidade do Extremo Sul Catarinense (UNESC). E-mail: melissawatanabe@unesc.net.

${ }^{3}$ Bacharel em Ciências Econômicas pela Universidade do Extremo Sul Catarinense (UNESC), Mestre pelo Programa de Pós-Graduação em Desenvolvimento Socioeconômico (PPGDS/UNESC) e Doutorando em Desenvolvimento Socioeconômico (PPGDS/UNESC). E-mail: ericosouzacosta@gmail.com.
} 


\section{ALLOCATION OF TECHNOLOGICAL RESOURCES FOR THIRD SECTOR ORGANIZATIONS}

Abstract: In the 1990s, a restructuring process in non-governmental organizations culminated both in the development of social entrepreneurship and in the professionalization of the third sector. One of the main difficulties of these organizations is still focused on raising funds to keep their activities running. Researchers in this area of knowledge indicate that the resources collected must come from different segments of society such as companies, people, sales of own material, among others. The technological field, although expanding, is still little explored as a means of raising funds for non-profit organizations. Thus, this research aims to list possibilities for capturing technological resources available to third sector entities, and to show how these resources can be accessed. As for the methodological processes, this is an exploratory, documentary and descriptive research, carried out using secondary data collected on the on the website of a non-profit technology company. Among the main results, the possibility of free access to tools such as Ad Grants, YouTube, GSuit was identified, as well as access to Microsoft Software licenses $\mathbb{R}$. Thus, the possibilities of fundraising using tools available in cyberspace can enhance the end activities of social organizations.

Keywords: Technology, non-profit organization, Google, TechSoup.

\section{INTRODUÇÃO}

O terceiro setor da sociedade é formado por organizações privadas com finalidades públicas, ou seja, organizações sem fins lucrativos que visam o bem comum (FERNANDES, 1994). Na década de 1980 uma série de escândalos de corrupção envolvendo tais organizações gerou desconfiança e uma redução significativa na capacidade de captação de recursos dessas organizações (SALOMON, 1997). Deste modo, no momento atual, a necessidade de legitimar as ações de empresas confiáveis culminou em um processo de reestruturação das organizações sem fins lucrativos na década de 1990, resultando no empreendedorismo social e na busca pela profissionalização do terceiro setor (FALCONER, 1999; OLIVEIRA, 2004).

Mesmo seguindo padrões de legitimação pautados em transparência, as organizações do terceiro setor ainda enfrentam inúmeros desafios na captação de recursos para a manutenção das suas atividades. Assim, conforme salientavam Cruz e Estraviz (2003) é importante buscar o fracionamento entre captação com empresas, pessoas, vendas de material próprio, dentre outros. De acordo com dados de instituições especialistas no terceiro setor tais como Captamos.org.br ${ }^{4}$, Rede Filantropia ${ }^{5}$ e Associação Brasileira de Captadores de

\footnotetext{
${ }^{4}$ Captamos - iniciativa da ABCR - é uma plataforma online totalmente gratuita voltada para a transmissão de conhecimento em mobilização de recursos para causas. Sua missão é fornecer conhecimento para pessoas, parceiros e organizações no processo de doação, capitação e missão das organizações de colaboração. Disponível em: <http://captamos.org.br>. Acesso em: 29 jul. 2019.

${ }^{5}$ Rede Filantropia é uma plataforma online que atua na disseminação do conhecimento técnico de gestão para organizações do Terceiro Setor por meio de publicações, eventos, treinamentos, consultorias coletivas e conteúdo online e impressos. Disponível em: <https://www.filantropia.ong>. Acesso em: 29 jul. 2019.
} 
Recursos $(A B C R)^{6}$, atualmente o campo tecnológico ainda é uma ferramenta pouco explorada pelas organizações do terceiro setor, mesmo em face da existência de diversas possibilidades.

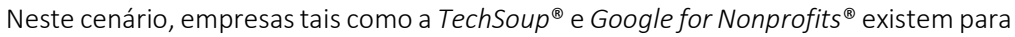
facilitar fomentos oriundos de materiais tecnológicos, tais como softwares de gestão por exemplo. Segundo a TechSoup $^{\circledR}$, as organizações se beneficiam com o implemento de ferramentas digitais e tecnológicas alcançando dinamismo e qualidade técnica para alcançar seus objetivos. Com a consolidação de um programa de doação de softwares, assistência técnica e informações, o potencial de atuação das organizações é ampliado.

O fomento tecnológico ainda é pouco estudado no meio científico, embora empiricamente venha ocorrendo a vários anos. Assim, esta pesquisa tem por objetivo verificar possibilidades de captação de recursos tecnológicos disponíveis às entidades do terceiro setor, e evidenciar de que maneira tais recursos podem ser acessados.

\section{CONTEXTUALIZAÇÃO DO TERCEIRO SETOR}

As organizações sem fins lucrativos na sua maioria desempenham um papel social aderente aos chamados Objetivos de Desenvolvimento Sustentável (ODS), os quais compõem a agenda 2030. As organizações sem fins lucrativos ou organizações não governamentais (ONGs), como também são chamadas, fazem parte do terceiro setor da sociedade, e, não tem dependência direta do governo, nem de empresas privadas. Tratam-se assim, de entidades da sociedade civil organizada com vistas a transformação social.

"O Terceiro Setor deve ser entendido como um movimento democrático que emerge da sociedade, sendo utilizada por ela para atender as suas necessidades e concretizar os direitos fundamentais reconhecidos expressa ou implicitamente pela ordem constitucional, mas que não são totalmente realizados" (PAES; VALLE; SANTOS, 2017, p. 178).

O Terceiro Setor tem suas origens muito antes do seu reconhecimento efetivo na década de 1970 nos Estados Unidos. Este setor foi originado da necessidade de efetivação dos direitos dos cidadãos, por isso partiu da sociedade civil organizada (PAES; VALLE;SANTOS, 2017), na qual, uma parte da população assumiu o compromisso de atuar em questões fora de alcance estatal e de desinteresse de empresas privadas (TRIGUEIRO; SANTOS, 2012). Assim, estas empresas não visam lucro para acionistas e não se configuram como dependentes da esfera governamental.

Na década de 1980 o Brasil presenciou um aumento significativo no número de

\footnotetext{
${ }^{6} \mathrm{ABCR}$ é uma organização sem fins lucrativos composta por captadores e mobilizadores de recursos com a missão de estabelecer uma ampla rede nacional para a promoção do desenvolvimento de laços, intercâmbio técnico e troca de experiências aos profissionais do Terceiro Setor. Disponível em: <https://captadores.org.br/>. Acesso em: 29 jul. 2019.
} 
organizações não governamentais, em meio a esse crescimento acelerado, percebeu-se a falta de fiscalização e aumento de fraudes e irregularidades nas ONGs, assim essas empresas passaram a ser desacreditadas (SALOMON, 1997). Percebendo-se a necessidade de restaurar a legitimidade de organizações sérias, na década de 1990 houve um forte movimento em direção a profissionalização do setor, o que veio a culminar no empreendedorismo social (OLIVEIRA, 2004).

De fato, o Terceiro Setor possui:

“[...] objetivos legítimos de realização de desejos e direitos de diferentes grupos populares, que podem ter necessidades diferenciadas, frutos dos processos históricos que são distintos entre si, mas amarrados pela necessidade coletiva da efetivação dos direitos fundamentais" (PAES; VALLE; SANTOS, 2018, P. 170).

Os Objetivos de Desenvolvimento Sustentável, são formados por 169 metas que visam a concretização dos direitos humanos de todos, equilibrando as dimensões econômica, social e ambiental do desenvolvimento Sustentável. Fruto de um trabalho extensivo entre a Organização das Nações Unidas (ONU) e outras instituições governamentais, privadas, e não governamentais, em setembro de 2015 foi lançada a Agenda 2030, que é um plano de ação para se alcançarem as metas dos ODS (NAÇÕES UNIDAS BRASIL, 2015).

Já os grandes setores da sociedade podem ser identificados como primeiro, segundo e terceiro setor. Assim o primeiro setor engloba as empresas governamentais, o segundo setor envolve as empresas privadas com finalidade de lucro, e o terceiro setor são as organizações sem fins lucrativos ou da sociedade civil organizada (TEIXEIRA, 2003). As atividades realizadas pelo terceiro setor destinam-se ao combate de desigualdades e tem direcionamento, principalmente, ao combate de problemas locais (RIBAS JÚNIOR, 2008). A representação dos três setores da sociedade pode ser observada na Figura 1.

Figura 1: Representação dos três setores da sociedade

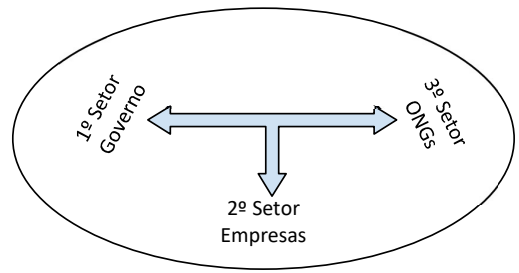

Fonte: Elaboração própria (2019)

A constituição do terceiro setor, ainda não está totalmente consolidada, ocorrendo por meio de organizações sem fins lucrativos, não-governamentais, e com o objetivo de gerar serviços de caráter público. Para Santos, Valle e Paes (2018) o terceiro setor é um ambiente complexo, com diversas possibilidades constitutivas, as quais são institucionalmente respaldadas desde a Constituição Brasileira de 1988. 
De modo específico, quanto a constituição das empresas não governamentais, Oliveira (2016) apresentou cinco atributos característicos do terceiro setor os quais podem ser identificados: a) por meio da sua constituição formal; b) estrutura básica não governamental; c) modelo próprio de gestão organizacional; d) não possuir fins lucrativos; e, e) permitir trabalho voluntário. Em síntese estes elementos foram compilados no Quadro 1, buscando-se elucidar as características de cada um dos atributos.

Quadro 1: Elementos característicos do Terceiro Setor

\begin{tabular}{|l|l|}
\hline Elementos & Características \\
\hline A constituição formal & $\begin{array}{l}\text { alguma forma de institucionalização, legal ou não, com um nível de } \\
\text { formalização de regras e procedimentos, para assegurar a sua } \\
\text { permanência por um período mínimo de tempo. }\end{array}$ \\
\hline Estrutura não governamental & são privadas, ou seja, não são ligadas institucionalmente a governos. \\
\hline Gestão própria & realizam sua própria gestão, não sendo controladas externamente. \\
\hline Sem fins lucrativos & $\begin{array}{l}\text { a geração de lucros ou excedentes financeiros deve ser reinvestida } \\
\text { integralmente na organização. Estas entidades não podem distribuir } \\
\text { dividendos de lucros aos seus dirigentes. }\end{array}$ \\
\hline Trabalho voluntário & $\begin{array}{l}\text { possui algum grau de mão-de-obra voluntária, ou seja, não } \\
\text { remunerada ou o uso voluntário de equipamentos, como a } \\
\text { computação voluntária. }\end{array}$ \\
\hline
\end{tabular}

Fonte: Adaptado de Oliveira (2016)

Juridicamente, o Terceiro Setor no Brasil é representado por uma pessoa jurídica de direito privado, englobando assim, associações, fundações, organizações religiosas e também partidos políticos (OLIVEIRA, 2016).

Ao encontro das necessidades sociais urgentes, o Terceiro Setor da Sociedade une a agilidade das empresas privadas e a abrangência de atendimento do Estado, para atingir suas finalidades. Mas existem ainda muitas dificuldades a serem superadas por estas instituições. Dentre as inúmeras dificuldades enfrentadas por essas organizações, sublinha-se a necessidade recursos para a realização de suas ações. Paes, Valle e Santos (2018, p. 170) defendem que:

“é necessário se discutir academicamente as principais formas de custeio financiamento dessas entidades, tanto para que haja transparência na alocação de recursos, quanto para que se busque a eficiência buscada pelas entidades do Terceiro Setor".

\section{A CAPTAÇÃO DE RECURSOS PARA O TERCEIRO SETOR}

A captação de recursos para organizações não governamentais tem suas características próprias, e deve estar alinhada aos objetivos (missão, visão e valores), da organização. De maneira geral a Figura 2, apresenta as possíveis fontes de recursos mais acessadas por organizações sem fins lucrativos. 
Figura 2: Fontes de captação de recursos

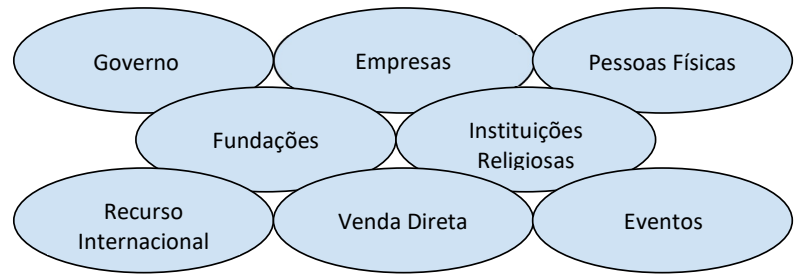

Fonte: Elaboração própria (2019).

A transparência nas ações desenvolvidas é um dos pré-requisitos à legitimidade dessas organizações, assim tais entidades devem agir de maneira franca, criando mecanismos de informação que auxiliem na divulgação de suas ações, impactos e retornos para a sociedade ou meio ambiente. De acordo com Trussel e Parson (2007) a falta de informação é um dos fatores que mais dificultam o recebimento de doações, e essas informações, podem estar relacionadas a eficiência de alocação dos recursos, a estabilidade financeira da organização não governamental, a própria reputação e sobre os benefícios gerados.

“A arrecadação de recursos de forma permanente exige que as organizações busquem formas criativas de elaborarem campanhas destinadas à arrecadação de fundos ou contribuições constantes, que, por sua vez, exigem uma forte competência das pessoas que estão a frente das organizações (SILVA, et al., 2018, p. 619)".

A Associação Brasileira de Captadores de Recursos ( $A B C R$ ) é uma instituição formal, que atua diretamente para a legitimidade e desenvolvimento das organizações sem fins lucrativos, reunindo profissionais da área da captação de recursos, promovendo cursos e capacitações (ABCR, 2019). Fundada em 1999 a ABCR, "tem como missão promover, desenvolver e qualificar a atividade de captação de recursos, vista hoje como um dos grandes desafios do Terceiro Setor" (ABCR, 2002, p.1). Deste modo, a ABCR vem ao longo dos anos auxiliando as organizações do Terceiro Setor a avançarem em suas missões institucionais.

Um elemento ainda pouco analisado no contexto da captação de recursos para as organizações sem fins lucrativos diz respeito aos recursos tecnológicos. Embora essa prática venha ocorrendo de maneira empírica desde a segunda metade dos anos 1980, com a fundação da CompuMento ${ }^{7}$ em 1987, ainda é um elemento pouco desenvolvido em pesquisas acadêmicas.

Neste cenário, entende-se por recursos tecnológicos, quaisquer ferramentas digitais, tais como softwares, licenças e outros elementos de auxílio gerencial das organizações do terceiro setor. Assim, torna-se pertinente compreender as diferentes maneiras de captação de recursos, as quais podem ser acessadas pelas organizações sem fins lucrativos, questionando-

\footnotetext{
${ }^{7}$ Atual TechSoup Global Network.
} 
se quais são as possibilidades de captação de recursos tecnológicos disponíveis às entidades do terceiro setor, e de que maneira tais recursos podem ser acessados?

\section{PROCEDIMENTOS METODOLÓGICOS}

Esta pesquisa apresenta uma abordagem qualitativa com um caráter exploratório, documental e descritivo, realizada por meio de dados secundários. Para a identificação de quais e como os recursos tecnológicos podem ser captados por organizações do terceiro setor realizou-se uma pesquisa exploratória, no site da empresa TechSoup $^{\circledR}$, empresa pioneira no ramo de tecnologias para o setor sem fins lucrativos. Observou-se primeiramente um histórico e o formato de atuação da empresa objeto de estudo, após isso buscou-se evidenciar quais os recursos tecnológicos possiveis para a utilização como foco na captação de recursos para as organizações sociais.

\section{RESULTADOS E DISCUSSÕES}

Esta seção apresenta-se dividida em duas perspectivas. A primeira buscou contextualizar a empresa estudada, sua área de atuação, bem como a justificativa da escolha desta na realização da presente pesquisa. Em um segundo momento buscou-se evidenciar as possibilidades existentes de recursos tecnológicos com vistas à captação de recursos do terceiro setor.

\section{TECHSOUP: BREVE HISTÓRICO E ATUAÇÃO}

A TechSoup Global Network é uma organização mundial de serviços de informática, a qual oferece soluções tecnológicas aos denominados "agentes de mudança". Entende-se aqui que estes agentes de mudança são organizações sem fins lucrativos voltadas ao desenvolvimento sustentável. Dentre as parcerias formadas com outras empresas do setor privado, destaca-se o programa de filantropia, o qual visa fornecer de maneira gratuita ou com valores acessíveis, diversos produtos tecnológicos para organizações sem fins lucrativos, desde sua fundação, a empresa já auxiliou outras ONGs na captação de mais de US\$ 10 bilhões de dólares em ferramentas tecnológicas e serviços de filantropia (TECHSOUP, 2019a).

A então chamada CompuMentor ${ }^{\circledR}$ iniciou suas atividades em 1987 como uma pequena organização sem fins lucrativos a qual funcionava como uma espécie de mentora para escolas e ONGs nos Estados Unidos. Entre os anos 2000 e 2002 a empresa lançou o TechSoup.org ं com intuito de compartilhar informações e recursos tecnológicos para empresas com finalidades sociais. Entre 2004 e 2005 a empresa passou a atender também bibliotecas públicas norte americanas, entre 2008 e 2009 expandiu suas atividades para a América Latina e Austrália. Em 
2012 com o projeto Asia-Pacific chegaram a mais 60 países. Entre os anos de 2014 e 2015 a foi presenciado um crescimento exponencial na instituição, com a adição de 63.000 (sessenta e três mil) ONGs ao seu banco de dados, adesão de países como China e Índia, bem como o lançando dos programa do Google for Nonprofits ${ }^{8}$, em parceria com a empresa Google e o programa Office 365 for Nonprofits ${ }^{9}$ em parceria com a Microsoft ${ }^{\circledR}$. Em 2018 já estavam presentes em 236 países. Atualmente são reconhecidos como uma empresa social a nível mundial. No início do ano de 2019, já eram mais de um milhão de organizações não governamentais beneficiadas (TECHSOUP, 2019b).

Neste contexto, a TechSoup Brasil foi lançada em 2009, a partir de uma parceria entre as empresas TechSoup e a Associação Telecentro de Informação e Negócios (ATN ${ }^{10}$ ) (TECHSOUP, 2019a). Por meio de uma plataforma online é possível pesquisar diversas soluções em tecnologia para as empresas do terceiro setor. No programa TechSoup Brasil acredita-se "que as organizações podem ter impacto ainda maior através do uso adequado da tecnologia" ("TECHSOUP BRASIL", 2009, p.1), assim também disponibilizam assistência, tanto na utilização quanto na manutenção das ferramentas tecnológicas.

\section{POSSIBILIDADES DE CAPTAÇÃO DE RECURSOS TECNOLÓGICOS}

Existem inúmeras possibilidades para captação de recursos tecnológicos destinados às organizações sem fins lucrativos. Desta forma a TechSoup pode ser considerada uma plataforma que possibilita o acesso a tais produtos. Dentre os principais parceiros, fornecedores de tecnologia estão grandes empresas, tais como Microsoft e Google . Esta pesquisa agrupa e descreve algumas das possibilidades de acesso a tecnologias digitais para as organizações do terceiro setor. Assim são apresentadas algumas das possibilidades disponibilizadas a tais organizações.

Dentre os benefícios, concedidos por meio do programa TechSoup Brasil, identificaram-se diversos softwares os quais podem ser selecionados por: doador; categoria; título, idiomas ou plataformas por exemplo. Não é a intenção deste trabalho esgotar os assuntos ou apresentar todas as possibilidades de captação a serem acessadas pela TechSoup Brasil, mas sim, evidenciar algumas das possibilidades que de captação de recursos para as ONGs além dos recursos já explanados na Figura 2.

Vale ressaltar que o programa TechSoup Brasil apresenta a sua sustentabilidade financeira por meio da cobrança de taxas administrativas, assim, os produtos são gratuitos para as organizações sem fins lucrativos, mas, em certas modalidades são essas taxas que permitem

\footnotetext{
${ }^{8}$ Google para organizações sem fins lucrativos.

${ }^{9}$ Office 365 para organizações sem fins lucrativos

${ }^{10}$ A empresa brasileira ATN é uma OSCIP sem fins lucrativos, fundada em 2006, destinada a apoiar os telecentros espalhados pelos Brasil, buscando melhorias nas condições sociais por meio da inclusão digital.
} 
a continuidade das atividades do programa a longo prazo, pois permitem que haja a manutenção dos seus escritórios (TECHSOUP BRASIL, 2009b)

Para os interessados, o primeiro passo é cadastrar a organizações no site do programa TechSoup Brasil11. Para tal, as organizações precisam ser elegíveis, ou seja, precisam estar aptas a participar do programa, assim devem comprovar que são empresas sem fiz lucrativos, e atender aos parâmetros de cada um dos doadores (TECHSOUP BRASIL, 2019a). A fim de exemplificação, serão apresentados critérios das empresas Microsoft ${ }^{\circledR}$ e Google ${ }^{\star}$.

O Google para Organizações Sem Fins Lucrativos no Brasil, fornece às organizações do terceiro setor acesso a certos produtos, ferramentas e serviços de sua empresa de maneira gratuita, dentre as possibilidades pode-se fazer uso do Ad Grants, YouTube e G Suit. No entanto, para ter acesso gratuito a essas ferramentas, a ONG deve atender as regras da Google para poderem acessar as ferramentas (TECHSOUP BRASIL, 2019b). Já a Microsoft ${ }^{\circledast}$ disponibiliza acesso a alguns produtos da empresa, por meio de um ciclo de renovação bianual. Dentre os benefícios disponíveis estão pacotes do Microsoft Office ${ }^{\star}$, instalação do Windows Server ${ }^{\circledR}$, Standard $^{\circledast}$ ou Datacenter (TECHSOUP BRASIL, 2019c). Quanto aos critérios de elegibilidade criou-se o Quadro 2.

Quadro 2: Critérios de elegibilidade para participar dos programas de doação dos parceiros da TechSoup Brasil.

\begin{tabular}{|l|l|l|}
\hline $\begin{array}{l}\text { Parceiro } \\
\text { TecShoup }\end{array}$ & Tipo de doação & Critérios de elegibilidade \\
\hline $\begin{array}{l}\text { Programa } \\
\text { Google }\end{array}$ & $\begin{array}{l}\text { Acesso as } \\
\text { ferramentas: Ad } \\
\text { Grants, You Tube e } \\
\text { G Suit }\end{array}$ & $\begin{array}{l}\text {-Ter uma conta válida da TechSoup Brasil; } \\
\text { - Deve se inscrever no website do Google para Organizações Sem Fins } \\
\text { Lucrativos no Brasil }\end{array}$ \\
& & $\begin{array}{l}\text { - Deve ser caracterizada como associação ou fundação designada como } \\
\text { OSCIP, UPF, OS, CEBAS ou de utilidade pública; } \\
\text { - Não são qualificadas neste programa, organizações governamentais, } \\
\text { hospitais e organizações de saúde, escolas, creches, instituições } \\
\text { acadêmicas e universidades }\end{array}$ \\
\hline $\begin{array}{l}\text { Programa } \\
\text { Microsoft }\end{array}$ & $\begin{array}{l}\text { Licenças de } \\
\text { Softwares }\end{array}$ & $\begin{array}{l}\text { - Ter uma conta válida da TechSoup Brasil; } \\
\text { - Ser uma organização com missão de beneficiar a comunidade local; } \\
\text { - As doações são destinadas a organizações sem fins lucrativos; } \\
\text { - Não são qualificadas neste programa, instituições educacionais, } \\
\text { organizaços políticas, redes de saúde e bibliotecas não públicas. }\end{array}$ \\
\hline
\end{tabular}

Fonte: dados da pesquisa

Os exemplos elencados no Quadro 2, representam algumas das possibilidades de

\footnotetext{
11 Link para registro https://www.techsoupbrasil.org.br/user/register. Ressalta-se que este foi o endereço eletrônico acessado no período de realização da pesquisa (TECHSOUP BRASIL, 2009c).

${ }^{12}$ Link para acesso https://www.google.com/intl/pt-BR/nonprofits/. Ressalta-se que este foi o endereço eletrônico acessado no período de realização da pesquisa (GOOGLE, 2019a).

${ }^{13}$ Escolas, creches, instituições acadêmicas e universidades possuem um programa específico, denominado Google for Education (GOOGLE, 2019b).
} 
captação de recursos de base tecnológica para organizações sem fins lucrativos.

\section{CONSIDERAÇÕES FINAIS}

Esta pesquisa teve por objetivo verificar possibilidades de captação de recursos tecnológicos para organizações do terceiro setor e de que maneira tais recursos podem ser acessados. Assim, com base em elementos identificados no website da empresa pioneira nesse tipo de doações, buscou-se descrever algumas das possibilidades de recursos tecnológicos que podem ser acessados. Deste modo abre-se espaço para que os profissionais do terceiro setor conheçam algumas das ferramentas disponíveis e busquem novas oportunidades de captação para suas organizações.

Dentre os resultados destacam-se ferramentas de gestão e produção de conteúdo, tais como Ad Grants, YouTube e GSuit, fornecidos pela Empresa Google e licenças de diversos softwares, fornecidos pela empresa Microsoft ${ }^{\circledR}$. A partir da aquisição destas ferramentas de gestão, de maneira gratuita ou com valores reduzidos, as organizações podem fazer a realocação de recursos financeiros para suas atividades finais, potencializando desta maneira sua atuação.

Este trabalho não se ateve ao aprofundamento de cada um dos elementos de captação tecnológica possíveis para as organizações sem fins lucrativos. No entanto, chama a atenção e dá visibilidade a tais possibilidades, demonstrando-as alternativas viáveis de captação. Ao usufruir dessas alternativas, as instituições estarão também aumentando a sua capacidade de atuação.

O presente trabalho abre espaço para futuras pesquisas, apresentando um elemento ainda pouco estudado no meio acadêmico que é a captação de recursos tecnológicos para o terceiro setor. Futuras pesquisas podem se aprofundar em estudos de caso com instituições que buscaram acesso a tais recursos, bem como o processo de implantação e operacionalização das ferramentas em seus sistemas de gestão. Como forma de inserção social, sugere-se uma cartilha instrutiva a fim de capacitar às organizações sem fins lucrativos a utilizarem tais ferramentas como uma adicional forma de captar recursos.

\section{AGRADECIMENTOS}

À Fundação de Amparo à Pesquisa e Inovação do Estado e Santa Catarina (FAPESC)

À Universidade do Extremo Sul Catarinense (UNESC). Ao Programa de Pós-graduação em Desenvolvimento Socioeconômico (PPGDS);

Ao Grupo de pesquisa em Estratégia, Competitividade e Desenvolvimento (GEComD);

Ao Conselho Nacional de Desenvolvimento Científico e Tecnológico (CNPE). 
O presente trabalho foi realizado com apoio da Coordenação de Aperfeiçoamento de Pessoal de Nível Superior -

Brasil (CAPES) - Código de Financiamento 001

\section{REFERÊNCIAS}

ABCR. Quem Somos?. Disponível em: <https://captadores.org.br/quem-somos/>. Acesso em: 17 jun. 2019.

ABCR. A Associação Brasileira de Captadores de Recursos. Disponível em: <https://captadores.org.br/>. Acesso em: 17 jun. 2019. CRUZ, C. M.;

ESTRAVIZ, M. Captação de Diferentes Recursos para Organizações Sem Fins Lucrativos. São Paulo: Global, 2003.

FALCONER, A.P. A promessa do terceiro setor: um estudo sobre a construção do papel das organizações sem fins lucrativos e do seu campo de gestão. Dissertação (Mestrado), FEA-USP, São Paulo: 1999.

FERNANDES, R. C. Privado porem público: o terceiro setor na América Latina. Rio de Janeiro: Relume-Dumara, 1994.

GOOGLE. Google para organizações sem fins lucrativos - Recursos de gerenciamento para organizações sem fins lucrativos. Disponível em: <https://www.google.com/intl/ptBR/nonprofits/>. Acesso em: 17 jun. 2019a.

GOOGLE. Google for Education - Soluções criadas para alunos e professores. Disponível em: $<$ https://edu.google.com/?modal_active=none>. Acesso em: 17 jun. 2019 b.

OLIVEIRA, E. M. Empreendedorismo social no Brasil: atual configuração, perspectivas e desafios-notas introdutórias. Revista da FAE, v. 7, n. 2, 2004.

PAES, J. E. S.; VALLE, M. D. T. do; SANTOS, J. E. S. O posicionamento estratégico do Terceiro Setor na Atualidade. Revista de Estudos e Pesquisas Avançadas do Terceiro Setor, v. 4, n. 2, p. 160-185, 2017. Disponível em:

<https://portalrevistas.ucb.br/index.php/REPATS/article/view/8863>. Acesso em: 4 jun. 2019.

RIBAS JUNIOR. O. T. Proposições Para A Melhoria No Desempenho De Agências De

Desenvolvimento Regional Utilizando As Experiências Em Curso Na Região Sul Do Brasil. 2008. Tese de Doutorado. Tese (Doutorado)-Universidade Federal de Santa Catarina, Curso de PósGraduação em Engenharia da Produção.

SALAMON, L. Estratégias para o fortalecimento do terceiro setor. In IOSCHPE, E. et. al. (Org.). 3o Setor e desenvolvimento social sustentado. Rio de Janeiro: Paz e Terra, 1997.

TECHSOUP. TechSoup Global Network. Disponível em: <https://meet.TechSoup.org/about- 
us/TechSoup-global-network.html>. Acesso em: 6 jun. 2019a.

TECHSOUP. TechSoup - History. Disponível em: <https://meet.TechSoup.org/aboutus/history.html>. Acesso em: 6 jun. 2019b.

TECHSOUP BRASIL. TechSoup Brasil - Quem Somos. Disponível em:

<https://www.TechSoupbrasil.org.br/about>. Acesso em: 17 jun. 2019a.

TECHSOUP BRASIL. TechSoup Brasil - Empresas de tecnologia anunciam parceria e doam software para organizações sem fins lucrativos. Disponível em:

<https://www.TechSoupbrasil.org.br/node/2038>. Acesso em: 17 jun. 2019b.

TECHSOUP BRASIL. TechSoup Brasil - Registre-se. Disponível em:

<https://www.TechSoupbrasil.org.br/user/register>. Acesso em: 17 jun. 2019c.

TECHSOUP BRASIL. TechSoup Brasil - Qualificação ao. Disponível em:

<https://www.TechSoupbrasil.org.br/eligibility_criteria>. Acesso em: 17 jun. 2019a.

TECHSOUP BRASIL. TechSoup Brasil - O Google para Organizações sem fins lucrativos.

Disponível em: <https://www.TechSoupbrasil.org.br/node/11827>. Acesso em: 17 jun. 2019b.

TECHSOUP BRASIL. TechSoup Brasil - Critério de Elegibilidade da Microsoft. Disponível em: $<$ https://www.TechSoupbrasil.org.br/eligibility_criteria/microsoft_eligibility_criteria>. Acesso em: 17 jun. 2019c.

TEIXEIRA, A.C. 2003. Identidades em construção: as organizações nãogovernamentais no processo brasileiro de democratização. São Paulo, Annablume/FAPESP/Instituto Polis, 207 p.

TRIGUEIRO, F. M. C.; SANTOS, F. A. Dos. UM ESTUDO SOBRE O TERCEIRO SETOR NA CIDADE DE CUIABÁ - MT. In: IX Congresso Virtual Brasileiro - Administração, Anais...2012. Disponível em: <http://www.convibra.com.br/artigo.asp?ev=25\&id=4884>. Acesso em: 17 jun. 2019.

TRUSSEL, J. M.; PARSONS, L. M. Financial Reporting Factors Affecting Donations to Charitable Organizations. Advances in Accounting, 2007. v. 23, 263-285. 